\title{
Setting boundary conditions on the part-set cuing effect
}

\author{
BARBARA H. BASDEN, DAVID R. BASDEN, BARBARA A. CHURCH, and PAT BEAUPRE \\ California State University, Fresno, California
}

\begin{abstract}
The effects of part-set cues were compared in free-recall and nonfree-recall retention tasks. During word presentation in Experiment 1, subjects read or completed fragments of list members. Output tasks were either fragment-completion or free-recall tests, both of which were cued or uncued. Although part-set cues inhibited recall, they did not influence fragment completion. Absence of negative cuing effects in fragment completion is contrary to research reported by Peynircioglu (1989) and suggests that cues are inhibitory when items are retrieved relationally but not when items are retrieved individually. Or, alternatively, cues may only be inhibitory when subjects consciously attempt retrieval. To test this idea, in Experiment 2, subjects were given indirect- or direct-memory associative tests, which were compared with free recall. In the indirect test, subjects were given stimulus words and were asked to provide a free associate for each; in the direct test, subjects were asked to recall an appropriate list member for each stimulus word. Part-set cues reduced recall but did not influence performance on either of the associative tasks. Overall, these results suggest that negative cuing is more likely to occur when items are retrieved relationally rather than individually.
\end{abstract}

The part-set cuing effect is a form of retrieval inhibition that occurs when a subset of previously studied material is presented during the retention test. Presentation of the subset inhibits retrieval of the remainder of the material relative to performance when the subset is not presented (Slamecka, 1968). This phenomenon is counterintuitive, and many models of memory phenomena would predict retrieval facilitation with part-set cues, not inhibition. Research on this persisting enigma in memory research was reviewed by Nickerson (1984).

One explanation of the part-set cuing effect is provided by the strategy-disruption hypothesis (Basden, Basden, \& Galloway, 1977). In this hypothesis, it is assumed that subjects develop organized retrieval plans or strategies in an attempt to increase test performance. When part-set cues are given at output, the subjects' normal order of recall is disrupted. This makes it impossible for the subjects to use the strategy that they have developed. Since they are not able to utilize their own organizational strategy, cued subjects are at a disadvantage in comparison with uncued subjects.

Peynircioglu (1989) recently tested the strategy-disruption hypothesis in a series of five experiments in which wordfragment completion was the retention task. In these ex-

\footnotetext{
Preparation of this article was supported in part by a Faculty Development Grant awarded to Barbara H. Basden. Portions of this research were reported by Barbara $A$. Church at the Joint Convention of the Rocky Mountain and Western Psychological Associations, April 28, 1989. Barbara A. Church is now at the University of Arizona; Pat Beaupre is now at Washington University. Reprint requests should be sent to Barbara H. Basden, Department of Psychology, California State University, Fresno, CA 93740-0011.
}

periments, subjects retrieved items individually to complete fragments of words that they had studied earlier. She argued that since item order is dictated by the experimenter in this task, strategy-disruption theory would not predict inhibition from part-set cues.

Contrary to this prediction, Peynircioglu by and large obtained inhibitory effects of part-set cues in wordfragment completion. She interpreted these results in terms of Rundus's (1973) competition-at-retrieval explanation of the part-set cuing effect. According to this explanation, words formed from the easily solved fragments compete with access to words formed from the more difficult fragments. The inhibitory effects that she obtained were reliable, but quite small.

One question raised by Peynircioglu's findings is whether the inhibitory effects obtained in fragmentcompletion tasks are of the same magnitude as those obtained in free recall. To answer this question, in Experiment 1 we examined the influence of cues on wordfragment completion and free recall. Strategy-disruption theory predicts greater inhibition from part-set cues in the recall task as opposed to the fragment-completion task. This prediction was tested in two parallel experiments in which free recall was the dependent variable in one experiment and fragment completion was the dependent variable in the other experiment.

In addition, in Experiment 1 we compared the magnitude of negative cuing effects obtained after subjects either generated or studied the list members. In this experiment, we also included a second, uncued retention test, to replicate the finding (Basden et al., 1977) that the inhibitory effects of cues dissipate when they are absent on a subsequent retention test. This finding is important, since it 
is predicted by strategy-disruption theory but not by competition-at-retrieval theory. Thus, when cues are absent, a subject's strategy cannot be disrupted; yet those cues would still be stronger than noncue items and hence more capable of competing with retrieval of noncue items.

\section{EXPERIMENT 1}

\section{Method}

Design. Two parallel $2 \times 2 \times 2$ factorial design experiments were conducted. The three independent variables were encoding task (study or generate), cuing condition (cued or uncued), and retention test (first or second). The first two factors were between subjects, while the last was a within-subjects factor. The two dependent variables were recall and fragment completion.

Subjects. A total of 120 introductory psychology students participated in the experiment; an equal number (15) were assigned to each of the eight conditions of the experiment.

Materials. A total of $\mathbf{4 8}$ words were drawn from the list used by Tulving, Schacter, and Stark (1982). To form the word fragments, four letters were deleted from each word, but, for each presentation of a fragmented word, a different set of four letters was deleted.

An Apple Ile computer was used to present the experimental materials and instructions. The subjects wrote their responses in test booklets. For the cued recall test, the subjects were presented with 12 randomly selected list members. For the cued fragment-completion task, the subjects were presented with 24 complete words and with 24 word fragments. For both the cue and the noncue test, half were taken from the studied list.

Procedure. The subjects in both input conditions were told that their retention would be tested later. In the generation conditions, the 24 word fragments were presented individually at a $17-\mathrm{sec}$ rate; the fragment was presented for the first $12 \mathrm{sec}$, and the completed word was then presented for $5 \mathrm{sec}$. In the study conditions, the 24 words were presented one at a time at a $17-\mathrm{sec}$ rate. For both encoding tasks, at the end of each item's presentation, the subject said the word aloud.

After a 30-sec duration math distractor task, the subjects were given the first retention task. For the recall task, the subjects were told to remember the words in any order that they found to be convenient. For the fragment-completion task, the subjects were instructed to complete each word fragment as best they could. The subjects were told that some of the fragments were from the list that they had studied, whereas others were not. Cued subjects were told that cues from the list, if provided, should aid their retention. A second 30-sec math distractor task preceded the second, uncued retention test. Both tests lasted $5 \mathrm{~min}$. The subjects' performance was scored by counting the number of noncue words completed or recalled.

\section{Results}

Means and standard deviations for retention performance on both tests are shown in Table 1; an alpha level

Table 1

Cued and Uncued Retention as a Function of Encoding and Retrieval Task

\begin{tabular}{|c|c|c|c|c|}
\hline \multirow{3}{*}{$\begin{array}{c}\text { Encoding } \\
\text { Task }\end{array}$} & \multicolumn{4}{|c|}{ Retention Task } \\
\hline & \multicolumn{2}{|c|}{ Recall } & \multicolumn{2}{|c|}{ Fragment } \\
\hline & Cued & Uncued & Cued & Uncued \\
\hline \multicolumn{5}{|c|}{ Test 1} \\
\hline $\begin{array}{l}\text { Study } \\
\text { Generate }\end{array}$ & $\begin{array}{l}5.13 \\
4.20\end{array}$ & $\begin{array}{l}6.27 \\
5.60\end{array}$ & $\begin{array}{l}7.07 \\
6.40\end{array}$ & $\begin{array}{l}6.20 \\
6.20\end{array}$ \\
\hline \multicolumn{5}{|c|}{ Test 2} \\
\hline $\begin{array}{l}\text { Study } \\
\text { Generate }\end{array}$ & $\begin{array}{l}5.27 \\
4.33\end{array}$ & $\begin{array}{l}6.00 \\
5.27\end{array}$ & $\begin{array}{l}7.13 \\
6.13\end{array}$ & $\begin{array}{l}6.40 \\
7.33\end{array}$ \\
\hline
\end{tabular}

of .05 was adopted for all comparisons. Type of input task did not significantly affect either recall $[F(1,56)=1.90]$ or fragment-completion performance $[F(1,56)=1.01]$. The interaction between type of encoding task and cuing condition was not significant, either for free recall $[F(1,56)$ $=3.14]$ or for fragment completion $[F(1,56)=2.15]$.

Both dependent variables yielded a significant interaction between retention test and cuing; for free recall, $F(1,56)$ $=5.30$, and for fragment completion, $F(1,56)=5.04$. For the recall data, simple tests of main effects indicated that cues significantly reduced recall on the cued retention test $[F(1,56)=4.84]$, but this effect was absent on the subsequent uncued retention test $(F<1)$. For the fragment-completion data, simple tests of main effects indicated that performance improved significantly between the two tests for subjects who had not received cues on the first retention test $[F(1,28)=8.46]$, but it did not improve for subjects who had received cues $(F<1)$. All other two- and three-way interactions were not significant.

These results support strategy-disruption theory, since cues significantly reduced performance on the recall task but did not affect performance on the fragment-completion task. These results are not consistent with Peynircioglu's (1989); our explanation for these differences is that her procedures may have encouraged active recall, whereas ours did not. In addition, cues were not significantly inhibitory on the second retention test-a result that we have obtained in previous research (Basden et al., 1977; Basden \& Draper, 1973).

Thus, negative cuing effects might occur with direct memory tests but not with indirect ones. It is possible to argue (cf. Gardiner, 1988; Peynircioglu, 1989) that subjects complete word fragments without attempting to retrieve items from the list, even when they are given directmemory instructions. Since conscious recollection would involve attempts to retrieve items, it could be that explicitmemory processes are disrupted by part-set cues but that implicit-memory processes are not.

\section{EXPERIMENT 2}

The purpose of Experiment 2 was to determine whether part-set cues inhibit performance equally in indirect- and direct-memory tasks. A paired associate testing procedure was used, so that the same dependent variable was measured in both tasks. Note that both tasks require the subjects to retrieve items individually; the only difference between the two is whether or not the subjects are consciously attempting to recall list members. The subjects were asked to free associate to each stimulus term in the indirect-memory test, and they were asked to recall a list member appropriate to each stimulus term in the directmemory test. The effect of part-set cues in free recall was compared with that in the paired associate tasks.

\section{Method}

Subjects. Seventy-two introductory psychology students at California State University, Fresno, participated in the experiment to fulfill course requirements. 
Materials. A set of $\mathbf{4 8}$ word pairs were selected from Palermo and Jenkins's (1964) word-association norms. The response terms were low associates of the stimulus terms, ranking fourth through sixth of the responses provided by the normative subjects. The word pairs were divided into two 24-word lists, designated as A and B. Half the subjects were tested with Set $A$ and half with Set $B$. In all conditions, the subjects also provided associated state-name responses to a list of 24 product-name stimulus terms. All materials and instructions were presented on IBM-compatible personal computers.

Design. The two independent variables were cuing condition (cued or uncued) and retrieval task (free recall, direct paired associate task, and indirect paired associate task); both factors were manipulated between subjects. The dependent variable was the number of critical items recalled.

Procedure. The subjects were tested individually on microcomputers. They typed their responses on the computer keyboard.

The experiment proper began with presentation of the response words at a 2-sec rate. The subjects were instructed to memorize these words for a later recall task. After word presentation, the subjects completed a simple association task in which they typed a state name as an associate to a product name displayed on computer screen (e.g., orangeFlorida). The subjects were allowed $30 \mathrm{sec}$ to complete this task, which was intended to disguise the true purpose of the indirect memory test. An initial recall test was administered next; it continued until the subject had not typed a response for $30 \mathrm{sec}$. The list was presented again at the same rate after the initial recall test. A second retention test immediately followed the second list presentation. The list was presented a second time, since a pilot study had obtained floor effects following a single presentation of the list.

In the free-recall test, cued subjects were shown a screen containing a random half of the list members as cues. Uncued subjects were shown a blank screen. The words typed by the subjects were displayed on the computer screen.

In the indirect-memory test, uncued subjects were provided with all 48 stimulus members of the word pairs and were asked to provide a free associate for each. Each response typed by a subject filled the blank adjacent to the next unused stimulus word shown on the computer screen. The subjects were reminded to provide an associate by the presence of a flashing A next to each stimulus term. Cued subjects were provided with half of the list-member response terms and half of the non-listmember response terms as cues. These response terms were presented next to the appropriate stimulus terms on the computer screen.

In the direct-memory test, uncued subjects were provided with all 48 stimulus members and were asked to recall the appropriate list-member response terms. They were instructed to provide an associate for each non-list-member stimulus term. A flashing R (for recall) or A (for associate) appeared with each stimulus term, to remind subjects which task to perform. The cued subjects were presented with the same materials as those given the indirect-memory test.

The subjects were given a total of $8 \mathrm{~min}$ to complete either the direct or the indirect retention tests. For both paired associate tests, all 48 stimulus terms and the information presented with them appeared simultaneously on the computer screen. Cues were randomly selected by the computer program for subjects in all conditions. All subjects were given a final free-recall test.

\section{Results}

The means and standard deviations for the two retention tests are displayed in Table 2. Recall did not differ as a function of either independent variable on the initial recall test $[F(2,66)=1.43, p>.05$, for type of retention test; and $F<1$, for cuing condition]. Thus the groups were initially equivalent.

Critical item recall on the second retention test was analyzed with a $2 \times 3$ factorial analysis of variance. The dependent variable was estimated for the uncued subjects by taking one half of their overall recall score and then comparing it with recall of the critical (noncue) items by
Table 2

Retention as a Function of Type of Test Task

\begin{tabular}{cccc}
\hline \multirow{2}{*}{$\begin{array}{c}\text { Test } \\
\text { Condition }\end{array}$} & \multicolumn{3}{c}{ Test Task } \\
\cline { 2 - 4 } & Indirect & Direct & Free Recall \\
\hline Cued & 2.17 & 4.50 & 4.17 \\
Uncued & 1.58 & 4.50 & 6.71 \\
\hline
\end{tabular}

the cued subjects. There was a significant main effect for type of retrieval task $[F(2,66)=18.41, p<.01]$. A post hoc test showed that performance in the free-recall task and the direct-memory task was not significantly different, but that the indirect-memory task produced significantly lower performance than did either of the other two tasks $[F(1,66)=1.72, p>.10]$. There was, however, a significant interaction between type of retrieval task and cuing condition $[F(2,66)=3.73, p=.03]$. Planned comparisons showed that in the recall task the uncued subjects performed significantly better than the cued subjects did. There was no significant difference between the cued and the uncued subjects in the other two retrieval tasks.

A correlated $t$ test was performed to compare recall scores and base rates of the subjects in the indirectmemory task. The base rate was obtained by counting the number of nonstudied response terms provided by the subjects in the indirect-memory task. Reliable levels of repetition priming were obtained, since indirect-memory scores were significantly higher than base rate scores $[t(1,23)=5.82, p<.01]$. The mean indirect-memory score was 1.88 , and the mean base rate score was .83 .

\section{GENERAL DISCUSSION}

The results support the hypothesis that the critical variable in partset cuing is whether items are retrieved individually or in groups. Partset cues did not influence performance in the paired associate tasks but did significantly reduce free-recall performance. Thus, it seems safe to conclude that the differential effect of cues in Experiment 1 was not due to the direct nature of the recall task and the indirect nature of the fragment-completion task.

A possible problem with the paired associate procedure is that subjects may have ignored the cues provided for them in the test tasks. In an attempt to prevent this from occurring, pairs containing cues were randomly intermingled with pairs not containing cues. Thus, in order to locate uncued pairs, subjects were forced to search through the cued pairs. To determine whether this procedure was effective, we looked at the tendency for subjects to repeat response terms-that is, to give cue words already provided on the recall test. Only a few subjects repeated the cue words, and the number of those who did so was no greater in the paired associate conditions than it was in the recall condition.

Overall, the results were consistent with prior research in indirect or implicit memory tasks (cf. Schacter, 1987). Performance was significantly better on the direct- or explicit-memory version of the paired associate task than it was in the indirect. In turn, performance was better in the indirect version than it was with no prior presentation of the items. We regard as coincidence the equivalent performance in the recall task and in the direct version of the paired associate task.

We conclude that the results from Experiment 1 are replicable and that part-set cues are inhibitory when items are retrieved in groups but not when they are retrieved individually. This leaves unexplained the difference between Peynircioglu's (1989) results and ours. One possibility is that practice effects interact with training conditions in the within- 
subjects design that she employed. This idea receives some support from the results obtained in Experiment 1. When subjects were not provided with cues in the fragment-completion task, their performance improved from the first retention test to the second; however, subjects who received cues on the first test did not improve on the second. Having experience in one testing condition apparently impaired performance in the other condition, thus reducing the practice effect. This type of intertrial negative cuing effect can be distinguished from that obtained in free recall. In free recall, part-set cues inhibit performance on the initial retention test and are not dependent on exposure of subjects to both the cue and the noncue conditions.

In conclusion, the results of these three experiments are taken as support for strategy-disruption theory. Subjects performed worse when partlist cues were provided in free recall but not when part-list cues were provided in tasks in which order of retrieval was imposed by the experimenter.

\section{REFERENCES}

Basden, D. R., Basden, B. H., \& Galloway, B. C. (1977). Inhibition with part-list cuing: Some tests of the item strength hypothesis. Journal of Experimental Psychology: Human Learning \& Memory, 3, 100-108.

BASDEn, D. R., \& DrAPER, J. S. (1973). Effect of cuing with list members in free recall as a function of number of categories, taxonomic frequency, and presentation order. Canadian Journal of Psychology, 27, 327-333.
GARDINER, J. M. (1988). Generation and priming effects in wordfragment completion. Journal of Experimental Psychology: Learning, Memory, \& Cognition, 14, 495-501.

Nickerson, R. S. (1984). Retrieval inhibition from part-set cuing: A persisting enigma in memory research. Memory \& Cognition, 12, 531-552.

PAlermo, D. S., \& Jenkins, J. J. (1964). Word association norms: Grade school through college. Minneapolis: University of Minnesota Press.

Peynircioglu, Z. F. (1989). Part-set cuing effect with word-fragment cuing: Evidence against the strategy disruption and increased-list-length explanations. Joumal of Experimental Psychology: Leaming, Memory, \& Cognition, 15, 147-152.

Rundus, D. (1973). Negative effects of using list items as recall cues. Journal of Verbal Learning \& Verbal Behavior, 12, 43-50.

SCHACTER, D. L. (1987). Implicit memory: History and current status. Journal of Experimental Psychology: Learning, Memory, \& Cognition, 13, 501-518.

Slamecka, N. J. (1968). An examination of trace storage in free recall. Journal of Experimental Psychology, 76, 504-513.

Tulving, E., Schacter, D. L., Stark, H. A. (1982). Priming effects in word-fragment completion are independent of recognition memory. Journal of Experimental Psychology: Human Learning \& Memory, 8, 336-342.

(Manuscript received November 5, 1990.) 